\title{
Reversal of cisplatin resistance in non-small cell lung cancer stem cells by Taxus chinensis var.
}

\author{
Y.Q. Jiang ${ }^{1}$, X.P. Xu' ${ }^{1}$, Q.M. Guo ${ }^{1}$, X.C. Xu ${ }^{1}$, Q.Y. Liu ${ }^{1}$, S.H. An ${ }^{1}$, J.L. Xu ${ }^{1}$, \\ F. $\mathrm{Su}^{1}$ and J.B. Tai ${ }^{1,2}$ \\ ${ }^{1}$ The First People's Hospital of Xiao Shan, Hangzhou, China \\ ${ }^{2}$ Zhejiang Chinese Medical University, China \\ Corresponding author: J.B. Tai \\ E-mail: jiabintai@163.com
}

Genet. Mol. Res. 15 (3): gmr.15038336

Received March 4, 2016

Accepted April 25, 2016

Published September 2, 2016

DOI http://dx.doi.org/10.4238/gmr.15038336

Copyright $(C 2016$ The Authors. This is an open-access article distributed under the terms of the Creative Commons Attribution ShareAlike (CC BY-SA) 4.0 License

\begin{abstract}
Drug resistance in cells is a major impedance to successful treatment of lung cancer. Taxus chinensis var. inhibits the growth of tumor cells and promotes the synthesis of interleukins 1 and 2 and tumor necrosis factor, enhancing immune function. In this study, T. chinensis var.-induced cell death was analyzed in lung cancer cells (H460) enriched for stem cell growth in a defined serum-free medium. Taxus-treated stem cells were also analyzed for Rhodamine 123 (Rh123) expression by flow cytometry, and used as a standard functional indicator of MDR. The molecular basis of T. chinensis var.-mediated drug resistance was established by real-time PCR analysis of $A B C C 1$, $A B C B 1$, and lung resistance-related protein $(L R P)$ mRNA, and western blot analysis of MRP1, MDR1, and LRP. Our results revealed that stem cells treated with higher doses of $T$. chinensis var. showed significantly lower growth inhibition rates than did $\mathrm{H} 460$ cells $(\mathrm{P}<0.05)$. The growth of stem and $\mathrm{H} 460$ cells treated with a combination of T. chinensis var. and cisplatin was also significantly inhibited $(\mathrm{P}<0.05) . \mathrm{Rh}-123$
\end{abstract}


was significantly accumulated in the intracellular region and showed delayed efflux in stem cells treated with $T$. chinensis var. $(\mathrm{P}<0.05)$, compared to those treated with verapamil. $T$. chinensis var.-treated stem cells showed significant downregulation of the $A B C C 1, A B C B 1$, and $L R P$ mRNA and MRP1, MDR1, and LRP $(\mathrm{P}<0.05)$ compared to H460 cells. Thus, T. chinensis var.-mediated downregulation of MRP1, MDR1, and LRP might contribute to the reversal of drug resistance in non-small cell lung cancer stem cells.

Key words: Non-small cell lung cancer; Drug resistance; Cisplatin; Taxus chinensis var.

\section{INTRODUCTION}

Lung cancer is the leading cause of cancer-related deaths in adults worldwide. Cancer stem cells (CSCs), a minority subgroup of tumor cells, are characterized by their undifferentiated phenotype. CSCs share some characteristics with normal stem cells, such as the capacity of unrestricted self-renewal, unlimited growth, and multipotent differentiation. The development of CSCs has been attributed to oncogenic mutations in normal stem cells (Singh and Chellappan, 2014); as a result, the characteristics of the former are different from those of other (bulk) cancer cells. CSCs are considered the driving force behind the initiation, development, recurrence, and chemoresistance of tumors. A widely acknowledged method for the isolation of CSCs is fluorescence-activated cell sorting (Wu and Alman, 2010); in this method, these cells are designated as a subpopulation of cells that expresses the cell surface markers CD133 and CD44 (Cojoc et al., 2015). In recent years, many CSCs have been successfully isolated from solid tumors, such as breast, colorectal, and pancreatic cancers (Moserle et al., 2010). In our previous study, putative lung-CSCs were successfully isolated, identified, and expanded from the non-small cell lung cancer (NSCLC) cell line A549, as well as from solid tumors in humans.

Recent studies have identified CSCs as major inducers of tumor drug resistance (Xue et al., 2012). Studies have indicated that CSCs induce an increase in drug resistance by increasing the expressions of multidrug-resistant genes and proteins. Mechanisms underlying multidrug resistance appear to be complex. The overexpression of ATP-binding cassette (ABC) transporter has been commonly identified as a multidrug resistance mechanism (Chen et al., 2015). ABC transporters are highly conserved ubiquitous transmembrane proteins that are abundant in the human body (Dean and Annilo, 2005); they transport peptides, complex lipids, nucleotides, and metabolic drugs, among others. Meanwhile, CSCs express high levels of $\mathrm{ABC}$ transporters, including $\mathrm{ABCB} 1$ and $\mathrm{ABCG} 2$, which mediate the extrusion of chemotherapeutic drugs, thereby inducing resistance to chemotherapy.

Several recent studies have shown that verapamil, cyclosporine, and their analogs, the extensively characterized P-gp inhibitors, can be used as reversal agents for multidrug resistance (Nobili et al., 2006; Perez-Tomas, 2006). However, a majority of the MDR reversal agents induce cardiovascular or renal toxicity in cancer patients, which limit their clinical applications. Therefore, novel strategies must be employed to overcome the drug resistant capacity of tumors. Overcoming the chemoresistance of NSCLC cells, enhancing the

Genetics and Molecular Research 15 (3): gmr.15038336 
sensitivity and effect of chemotherapeutic drugs, and prevention of recurrence and metastasis are the current major fields of cancer research. Moreover, extensive efforts have been made to synthesize novel reversal agents that are non-toxic and highly specific multidrug resistance modulators.

Taxus chinensis var. is a protected species of yew specific to China; extracts from many parts of this tree are used in traditional Chinese medicine against cancer, nephropathy, and rheumatism. T. chinensis var. has over 40 effective components, including paclitaxel, Taxus polysaccharides, baccatin III, alkaloids, and terpenes (Martens and Mithöfer, 2005). Of these, paclitaxel has been researched extensively for its therapeutic properties. Despite this, the water-soluble bioactive Taxus polysaccharides have drawn more attention for their antitumor activity. Recent studies have suggested that Taxus polysaccharides have potent immunomodulatory, anti-inflammatory, antiviral, and glycemia-inhibitory properties (Fan et al., 2012; Hua et al., 2012). The primary focus of several previous phase-II and -III clinical trials has been to test the efficacy of Taxus polysaccharides in treating lung cancer. However, the potential reversal effect of $T$. chinensis var. on drug resistance in lung CSCs has been rarely studied. In this study, we demonstrated the chemoresistant activity of NSCLC stem cells (established by sphere formation), and determined the role of T. chinensis var. in reversing this chemoresistance.

\section{MATERIAL AND METHODS}

\section{Cell lines, cell and sphere culture, and screening for cancer stem cells}

The human NSCLC cell line H460, obtained from American Type Culture Collection (ATCC, Manassas, VA, USA), was grown in DMEM/F12 (Gibco, Waltham, MA, USA) medium supplemented with $10 \%$ fetal bovine serum and penicillin-streptomycin at $37^{\circ} \mathrm{C}$ in a humidified incubator with $5 \% \mathrm{CO}_{2}$.

The cells were grown on ultra-low attachment plates (Corning, Corning, NJ, USA) and plated at a density of $5 \times 10^{6}$ cells $/ \mathrm{mL}$ in serum-free medium containing $20 \mathrm{ng} / \mathrm{mL}$ epidermal growth factor (EGF) (Gibco), $20 \mathrm{ng} / \mathrm{mL}$ basic fibroblast growth factor (bFGF) (PeproTech, Rocky Hill, NJ, USA), 2\% B27 (Invitrogen, Waltham, MA, USA), and $5 \mu \mathrm{g} / \mathrm{mL}$ insulin (Gibco) at $37^{\circ} \mathrm{C}$ in a humidified incubator with $5 \% \mathrm{CO}_{2}$, to obtain spherical cells. The culture medium was supplemented with additional growth factors twice a week. Sphere cells were collected by centrifugation at $503 \mathrm{~g}$ for $3 \mathrm{~min}$ at $37^{\circ} \mathrm{C}$. The supernatant was discarded, a single cell suspension was obtained, and the suspension was cultured to regenerate spheres.

\section{Cell counting kit-8 (CCK-8) cell survival assay}

T. chinensis var. stock solution was prepared with water. The viability of cells treated with $T$. chinensis var. and a combination of $T$. chinensis var. and cisplatin was detected by a standard CCK-8 assay (Dojindo, Kumamoto, Japan), according to the manufacturer protocol. H460 cells or stem cells were seeded on 96-well plates at a density of 5000 cells per well, suspended in $100 \mu \mathrm{L}$ culture medium, and allowed to adhere for $24 \mathrm{~h}$. Subsequently, $T$. chinensis var. or cisplatin (positive control) (Sigma-Aldrich, St. Louis, MO, USA) (Chu et al., 2014) was added to the wells at varying concentrations and the cells were cultured for 72

Genetics and Molecular Research 15 (3): gmr.15038336 
$\mathrm{h}$; an untreated control group was also included. CCK-8 solution $(10 \mu \mathrm{L})$ was added to each well and the plates were incubated for $2 \mathrm{~h}$. The absorbance (optical density at $490 \mathrm{~nm}$ ) of the cultures was determined using a microplate reader (Bio-Rad, Hercules, CA, USA).

\section{Flow cytometric analysis of the effect of T. chinensis var. on the accumulation and efflux of Rhodamine 123 (Rh-123)}

Rh-123 (Sigma-Aldrich) is a fluorescent probe, which causes less damage to cells than smaller fluorescent chemotherapeutic drugs; therefore, it is an ideal alternative for the study of the role of P-gp in cancer. The accumulation of Rh-123 in H460 stem cells was determined by flow cytometry. The cells were harvested by treating with $0.02 \%$ trypsin and centrifuging at $503 \mathrm{~g}$ for $3 \mathrm{~min}$ at $37^{\circ} \mathrm{C}$. The cells were then re-suspended at a density of $1 \times 10^{6} \mathrm{cells} / \mathrm{mL}$ and incubated in culture medium containing phosphate-buffered saline (PBS), $600 \mu \mathrm{g} / \mathrm{mL} T$. chinensis var., or $20 \mu \mathrm{M}$ verapamil and $5 \mu \mathrm{M} \mathrm{Rh}-123$ at $37^{\circ} \mathrm{C}$ for $0,30,60,90$, or $120 \mathrm{~min}$.

Rh-123 efflux from cancer cells was detected by incubating the cells in medium containing $T$. chinensis var. or verapamil, and subsequently in medium containing $1 \mu \mathrm{g} / \mathrm{mL}$ $\mathrm{Rh}-123$ for an additional 0, 5, 15, 30, or 60 min.

The cells were then washed twice with ice-cold PBS, suspended, and analyzed at $530 \mathrm{~nm}$ using a BD FACS Aria II flow cytometer (BD, Franklin Lakes, NJ, USA) supplied with a 488-nm laser.

\section{Real-time polymerase chain reaction (real-time-PCR)}

The effect of $T$. chinensis var. on the gene expression levels of key drug resistance genes $A B C C 1, A B C B 1$, and $L R P$ was determined by real-time-PCR.

Total RNA was extracted from the cells, using TRIzol reagent (Invitrogen). Singlestrand cDNA was synthesized from $1 \mu \mathrm{g}$ total RNA, using the PrimeScript ${ }^{\mathrm{TM}}$ RT reagent kit (TaKaRa, Otsu, Japan) as per the manufacturer protocol. RT-PCR was performed in the ABI PRISM 7500 Real-Time PCR system (Applied Biosystems, Foster City, CA, USA), using the primers summarized in Table 1. The PCR conditions were set as follows: initial denaturation at $95^{\circ} \mathrm{C}$ for $3 \mathrm{~min}$, followed by 40 cycles of denaturation at $95^{\circ} \mathrm{C}$ for $30 \mathrm{~s}$, annealing at $55^{\circ} \mathrm{C}$ for $20 \mathrm{~s}$, and extension at $72^{\circ} \mathrm{C}$ for $20 \mathrm{~s}$.

\begin{tabular}{|c|c|}
\hline Gene & Sequence \\
\hline \multirow{2}{*}{$A B C C 1$} & F primer: 5'-TAATCCCTGCCCAGAGTCCA-3' \\
\hline & R primer: 5'-ACTTGTTCCGACGTGTCCTC-3' \\
\hline \multirow[t]{2}{*}{$A B C B 1$} & F primer: 5'-ACCTGTGAAGAGTAGAACATGAAG-3' \\
\hline & \begin{tabular}{|l|} 
R primer: 5'-GCTTCCGTTGCACCTCTCTT-3' \\
\end{tabular} \\
\hline \multirow[t]{2}{*}{$L R P$} & F primer: 5'-GTCTTCGGGCCTGAGCTGGTGTCG -3' \\
\hline & R primer: 5'-CTTGGCCGTCTCTTGGGGGTCCTT -3' \\
\hline \multirow[t]{2}{*}{ GAPDH } & F primer: 5'-TGTTGCCATCAATGACCCCTT -3' \\
\hline & R primer: 5'-CTCCACGACGTACTCAGCG -3' \\
\hline
\end{tabular}

\section{Western blot analysis to determine the effect of T. chinensis on the expression of key drug resistance proteins $M R P 1, M D R 1$, and LRP}

The culture medium was discarded and the cells were lysed to extract total protein. The 
protein concentration was detected using a BCA protein assay kit (Pierce, Rockford, IL, USA) (Peng et al., 2016). The protein samples $(30 \mu \mathrm{g})$ were loaded on a $10 \%$ SDS polyacrylamide gel and electrophoresed, and subsequently transferred onto a polyvinylidene difluoride membrane (Roche, Basel, Switzerland). The membrane was blocked with 5\% non-fat milk at $25^{\circ} \mathrm{C}$ for $1 \mathrm{~h}$, and subsequently incubated with specific antibodies against MRP1 (1:1000), MDR1 (1:1000), LRP (1:1000) and GAPDH (1:1000) (ProteinTech, Chicago, IL, USA). The membrane was then incubated with a horseradish peroxidase-conjugated polyclonal secondary antibody (1:2000) in 5\% non-fat milk. Western-blot signals were detected using an enhanced chemiluminescence kit (Merck-Millipore, Darmstadt, Germany).

\section{Statistical analysis}

Data are reported as means \pm standard deviations of at least three independent experiments. The data were analyzed using the Student $t$-test or one-way analysis of variance (ANOVA), using the SPSS 17.0 statistical software package (IBM, Armonk, NY, USA). P values $<0.05$ were considered statistically significant.

\section{RESULTS}

\section{Sphere formation}

Stem cell production from an NSCLC cell line (H460) was propagated by growing the cells in a serum-free sphere-promoting media. A number of studies have suggested that $\mathrm{H} 460$ spherical stem cells could be induced in vitro by culturing on an ultra-low attachment plate. The culture medium was replaced every 2 days during the 10-day incubation period. Images of the tumor spheres were captured by microscopy (Figure 1). The sphere cells were round, with a regular shape and defined borders, and a possibly larger size. Spheres were able to reproduce up to at least three generations, and were maintained for more than 30 generations, indicating that the $\mathrm{H} 460$ sphere-derived cells were capable of self-renewal. Third-generation H460 sphere cells were used as lung CSCs in all subsequent experiments.

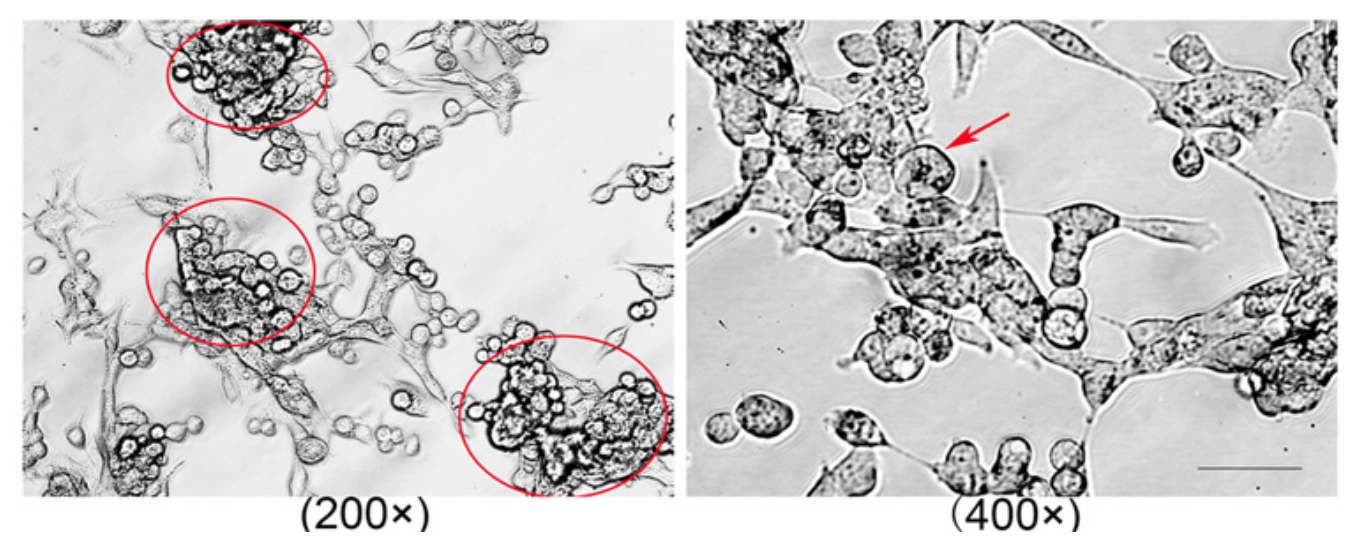

Figure 1. Sphere formation. Representative micrographs of spheres formed by H460 cell line were shown above.

Genetics and Molecular Research 15 (3): gmr.15038336 


\section{Effect of $T$. chinensis var. on cell survival}

The cytotoxicity induced by T. chinensis var. in H460 cells and H460-derived stem cells was evaluated by treating the cells with varying concentrations of $T$. chinensis var. for 72 $\mathrm{h}$. The cell viability was detected by a standard CCK-8 assay. A dose-dependent increase in cytotoxicity was observed in the cells, especially the H460 cells. The half-maximal inhibitory concentration was determined to be $783.4 \mu \mathrm{g} / \mathrm{mL}$ in $\mathrm{H} 460$ cells and $1449 \mu \mathrm{g} / \mathrm{mL}$ in $\mathrm{H} 460$ stem cells. The results revealed that $\mathrm{H} 460$ cells were more sensitive to T. chinensis var. than $\mathrm{H} 460$ stem cells (Figure 2A).
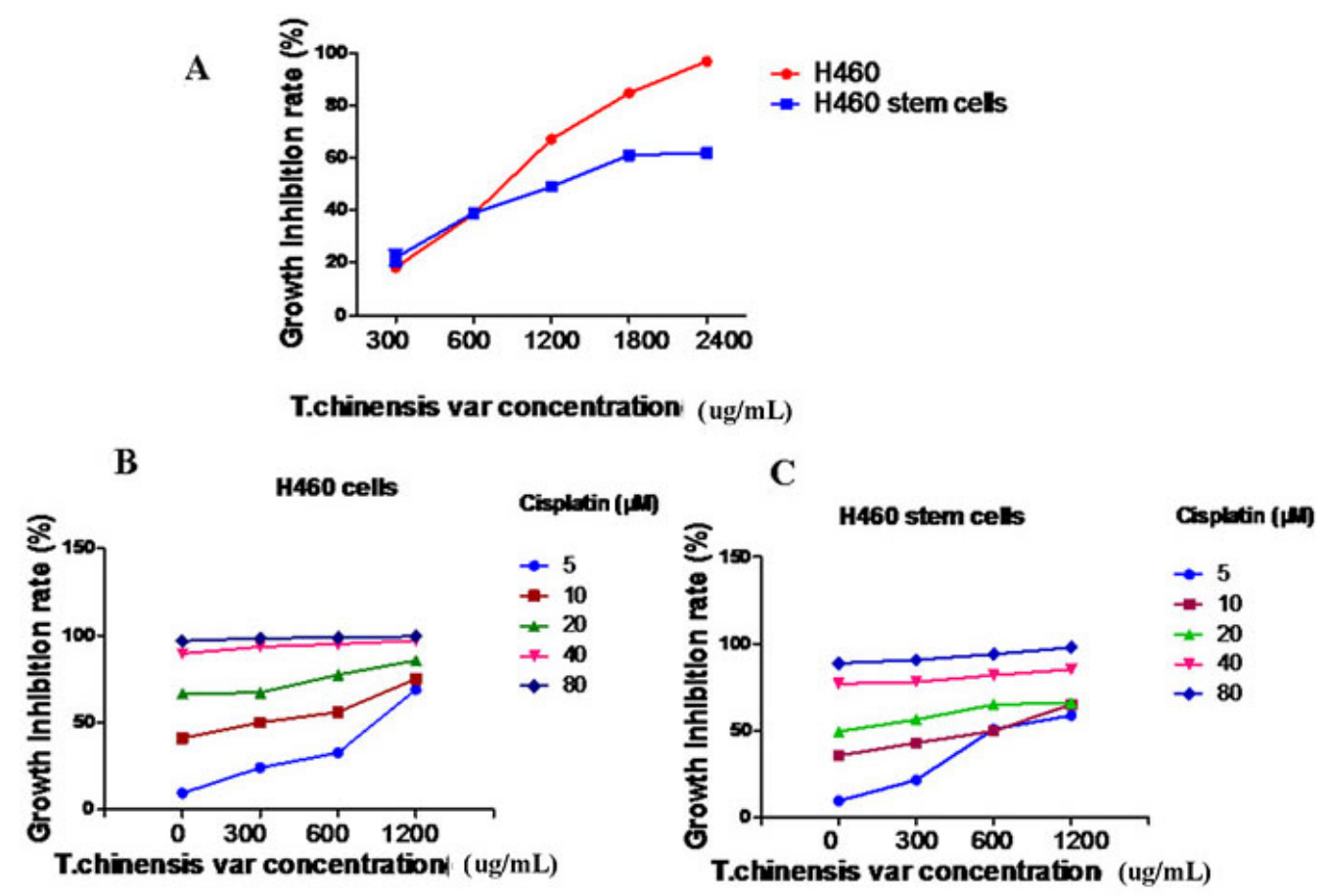

Figure 2. Cytotoxicity assay. A. H460 cells and H460 stem cells treated with varying concentrations of Taxus chinensis var. for $72 \mathrm{~h}$. Cell viability was determined by CCK-8 assay. B. C. Cell viability was assayed after H460 cells and $\mathrm{H} 460$ stem cells were treated with a combination of $T$. chinensis var. and cisplatin.

\section{Effect of a combination of $T$. chinensis var. and cisplatin on cell survival}

Cisplatin is an effective chemotherapeutic drug that is often used to treat lung cancer. The role of T. chinensis var. in reversing chemoresistance towards cisplatin was investigated in $\mathrm{H} 460$ cells and stem cells by treating the cells with a combination of the two at varying concentrations, and evaluating the subsequent rates of growth inhibition (Figure 2B and 2C). The interaction between the two drugs was evaluated based on the $\mathrm{Q}$ value. In this method, CI $<0.55$ indicated strong antagonism, $0.55<\mathrm{Q}<0.85$ indicated antagonism, $0.85<\mathrm{Q}<1.15$ was indicative of an additive effect, and $1.15<\mathrm{Q}<2.00$ indicated synergism. The $\mathrm{Q}$ values were calculated using the following formula: 


$$
\mathrm{Q}=\mathrm{E}(\mathrm{a}+\mathrm{b}) /(\mathrm{Ea}+\mathrm{Eb}-\mathrm{Ea} \times \mathrm{Eb})
$$

(Equation 1)

where $\mathrm{E}$ denotes the inhibition rate, $\mathrm{E}(\mathrm{a}+\mathrm{b})$ is the inhibition rate of a combination of a (drug $\mathrm{a}$; for example, T. chinensis var.) and b (drug b; for example, cisplatin), and $\mathrm{Ea}$ and $\mathrm{Eb}$ denote the inhibition rates of a and b alone. T. chinensis var.:cisplatin treatment ratios of $600 \mu \mathrm{g} / \mathrm{mL}: 5$ $\mu \mathrm{M}$ and $600 \mu \mathrm{g} / \mathrm{mL}: 40 \mu \mathrm{M}$ showed potential antagonism in $\mathrm{H} 460$ cells, while ratios of $300 \mu \mathrm{g} /$ $\mathrm{mL}: 5 \mu \mathrm{M}$ and $600 \mu \mathrm{g} / \mathrm{mL}: 10 \mu \mathrm{M}$ showed antagonism in H460 stem cells.

\section{Flow cytometric analysis of accumulation and efflux of Rh-123}

Rh-123 is often used as a substrate of P-gp, which accumulates in the mitochondria, and is transported by MDR1. Elevated expressions of P-gp on the membranes of cancer cells play a vital role in the efflux of chemotherapeutic drugs, eventually resulting in a relatively low (and effective) drug concentration with the cells. Verapamil, a P-gp inhibitor, was employed as a positive control in this study. The inhibitory effect of $T$. chinensis var. on P-gp transport was determined by measuring the fluorescence of (the remaining) intracellular Rh-123 using a flow cytometer. Fluorescent units were used to represent the content of Rh-123 remaining in the cells. As shown in Figure 3, the fluorescent intensity of the control group peaked after a 30-min incubation period, and showed no difference for up to $120 \mathrm{~min}$. Both verapamil and $T$. chinensis var. induced the accumulation and retention of Rh-123. Verapamil induced a quick and significant intracellular accumulation of Rh-123 in H460 stem cells $(\mathrm{P}<0.05)$, while incubation with $T$. chinensis var. for $90 \mathrm{~min}$ led to a statistically significant, 2-fold increase in fluorescent units, compared to that seen in the control group $(\mathrm{P}<0.05)$. That is, T. chinensis var. delayed the retention of Rh-123 compared to verapamil $(\mathrm{P}<0.05)$. This indicated that $T$. chinensis var. had a P-gp inhibitory effect on MDR reversal.
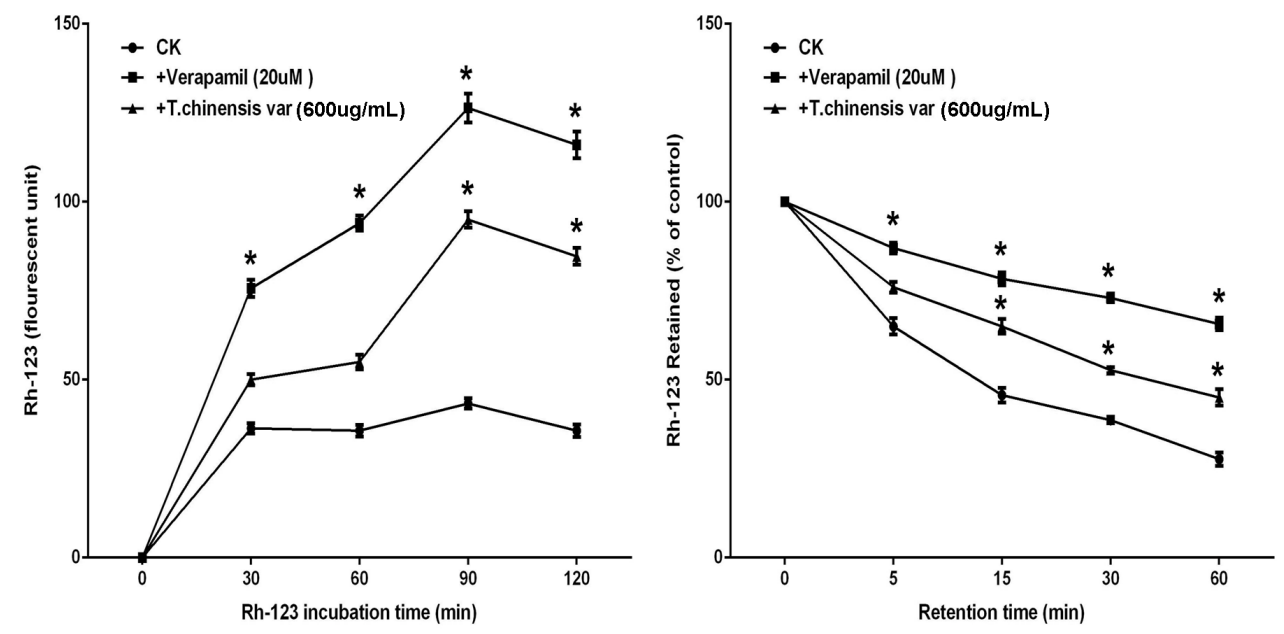

Figure 3. Analysis of accumulation and efflux of Rh-123 in $\mathrm{H} 460$ stem cells. ${ }^{*} \mathrm{P}<0.05$.

Expression of $A B C C 1$ (MRP1), ABCB1 (P-gp/MDR1), and LRP in NSCLC stem cells

The molecular basis of the reversal effect of $T$. chinensis var. on drug resistance 
was investigated by RT-PCR and western blot analyses of the levels of $A B C C 1, A B C B 1$, and LRP mRNA and their resultant proteins, respectively, in these cells. H460 stem cells showed significantly high levels of $A B C C 1, A B C B 1$, and LRP mRNA and MRP1, MDR1, and LRP proteins $(\mathrm{P}<0.05)$ compared to $\mathrm{H} 460$ cells (Figure 4A and 4B). Incubation with $T$. chinensis var. for $72 \mathrm{~h}$ resulted in a significant decrease in these mRNA and protein levels in the H460 stem cells, in comparison with that in the untreated H460 stem cells $(\mathrm{P}<0.05)$. The downregulation of mRNA and protein levels was found to be dose-dependent. These results indicate that $T$. chinensis var. reversed the multidrug resistant capacity of NSCLC stem cells by suppressing the expression of various $\mathrm{ABC}$ transporters; therefore, this was hypothesized to be the mechanism underlying the reversal effect of $T$. chinensis var. on chemoresistance in NSCLC stem cells.

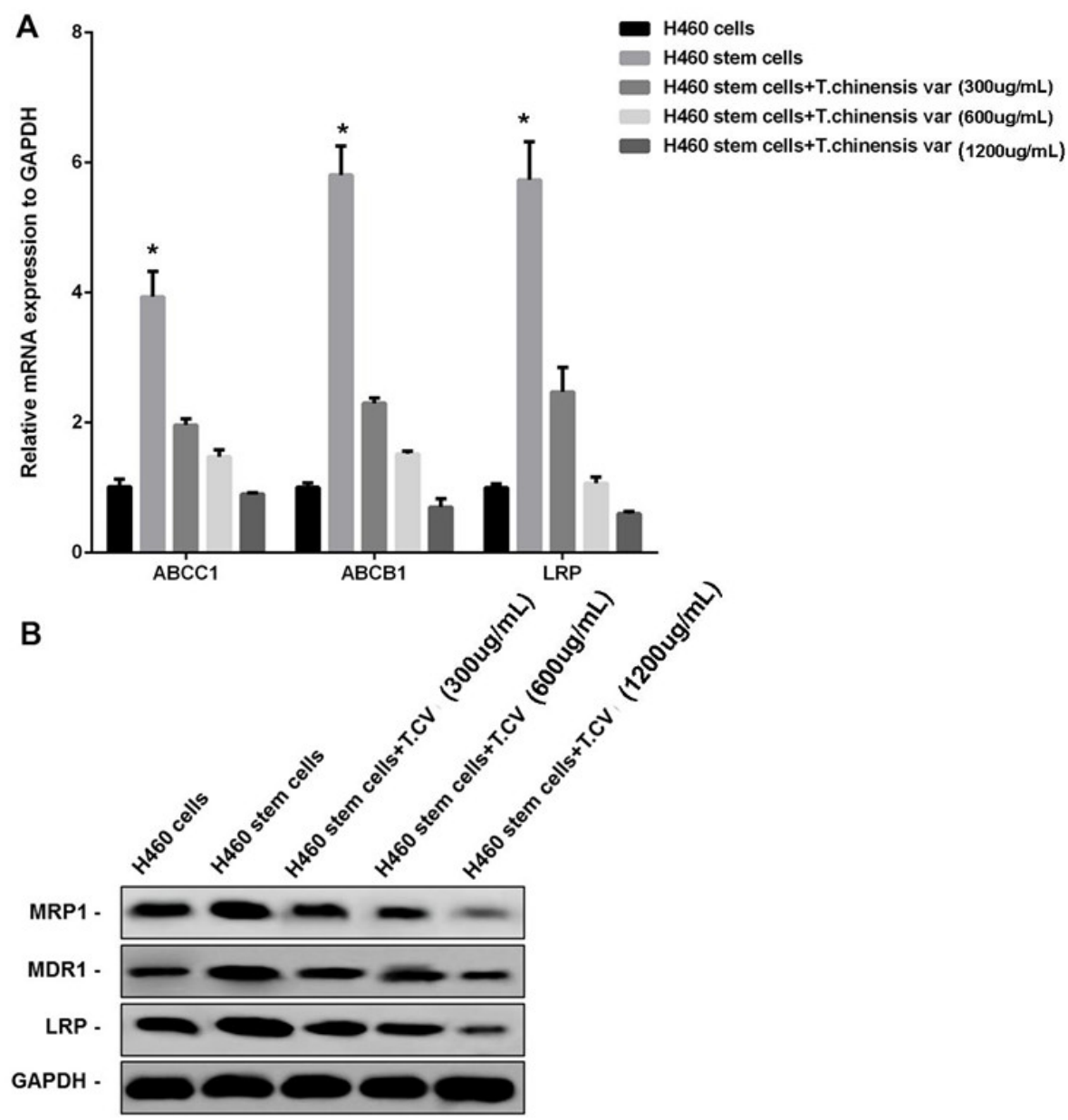

Figure 4. Analysis of levels of mRNA and proteins. A. Expression levels of $A B C C 1, A B C B 1$, and $L R P$ mRNA in cancer cells in the presence or absence of Taxus chinensis var. B. Expression levels of MRP1, P-gp/MDR1, LRP proteins in cancer cells in the presence or absence of T. chinensis var. Results shown above are representative of at least three individual experiments.

Genetics and Molecular Research 15 (3): gmr.15038336 


\section{DISCUSSION}

Multidrug resistance to cisplatin, wherein cancer stem cells are believed to impede the success of therapy, is a major challenge in the treatment of NSCLC. Therefore, several researchers are attempting to develop methods to reverse the chemoresistance of cancer stem cells. In this study, we developed a method to generate self-renewing and drug-resistant stem cells from the $\mathrm{H} 460$ cell line via sphere propagation, utilizing ultra-low-adherent substrates and growth factors such as EGF, bFGF, and B27, as described in previous studies (Coulon et al., 2011; Su et al., 2013). A number of studies have reported that cisplatin, widely used as a therapeutic agent against NSCLC, causes severe side effects (Karasawa and Steyger, 2015). However, a new anticancer agent extracted from $T$. chinensis var. has been reported to show anticancer activity without any accompanying organ toxicity (Cui et al., 2015; Zhao et al., 2015). T. chinensis polysaccharides, major components of the T. chinensis decoction extracts, present immunomodulatory, antitumor, anti-inflammatory, anti-viral, oxidation resistant, radiation resistant, hepatoprotective, and blood sugar/blood lipid reducing properties (Bai et al., 2015). In this study, we determined the therapeutic effect of an aqueous extract of $T$. chinensis var. on chemoresistant NSCLC stem cells propagated from a sphere-forming experiment. The results of the cell viability assay revealed that $\mathrm{H} 460$ stem cells were significantly resistant to high doses of $T$. chinensis var. In particular, we found that a relatively low dose of $T$. chinensis var. combined with cisplatin sensitized H460 stem cells to apoptosis.

Furthermore, fluorescence measurements indicated that $T$. chinensis var. could significantly enhance the accumulation of intracellular Rh-123 in H460 stem cells, which indicated that this extract was capable of inhibiting the activity of P-gp. P-gp is an ABC membrane transporter that can mediate the efflux of drugs from cells, causing chemotherapy failure. The results of this study showed that $T$. chinensis var. could be an effective P-gp inhibitor; however, the mechanism involved remains to be elucidated.

Internalization of the multidrug-resistant $\mathrm{ABC}$ transporter family is believed to be the most critical mechanism inducing cisplatin resistance. The ABC superfamily of proteins are known to transport chemotherapeutic drugs to facilitate extracellular ATP hydrolysis (in order to release energy), thereby lowering the drug concentration in the cell; this in turn results in drug resistance (Kuromori et al., 2011) So far, three ABC transporters, P-gp (MDR1, encoded by $A B C B 1$ ), MRP1 (encoded by $A B C C 1$ ), and the breast cancer resistance protein BCRP (encoded by $A B C G 2$ ), have been associated with chemoresistance. A number of studies have shown that the resistance of CSCs to anticancer drugs could be due to the upregulation of these genes and proteins. These proteins are capable of reducing the efficacy of anticancer agents, such as the apoptotic function of $T$. chinensis var. The mechanism of $T$. chinensis var.mediated reversal of multidrug resistance of lung cancer stem cells was further explained by assessing the mRNA and protein levels of these $\mathrm{ABC}$ transporters in the lung cancer cells. We observed high quantities of $A B C B 1, A B C B 2$, and $L R P$ mRNA and MDR1, MRP1, and LRP in drug-resistant $\mathrm{H} 460$ stem cells. Furthermore, the tested concentrations of $T$. chinensis var. were sufficient to suppress the expression of these mRNA and proteins.

In summary, our data confirmed that the inhibition of $A B C B 1, A B C B 2$, and $L R P$ mRNA and MDR1, MRP1, and LRP induced by T. chinensis var. reduced the chemoresistance of H460 stem cells. These results indicate that a combination of $T$. chinensis var. and other drugs in anticancer therapy could be a potent strategy for the effective treatment of NSCLC.

Genetics and Molecular Research 15 (3): gmr.15038336 


\section{Conflicts of interest}

The authors declare no conflict of interest.

\section{ACKNOWLEDGMENTS}

Research supported by grants provided by the Foundation of Hangzhou Technology Bureau (\#20130733Q45) and the Foundation of XiaoShan Technology bureau (\#2013301).

\section{REFERENCES}

Bai XY, Lü JM, Zhou YY, Zhu ZR, et al. (2015). Chemical constituents of Taxus chinensis var. mairei cell cultures. Yao Xие Xиe Bao 50: 70-74.

Chen Z, Shi T, Zhang L, Deng M, et al. (2015). Mammalian drug efflux transporters of the ATP binding cassette (ABC) family in multidrug resistance: A review of the past decade. Cancer Lett. pii: S0304-S3835.

Chu DJ, Yao DE, Zhuang YF, Hong Y, et al. (2014). Azithromycin enhances the favorable results of paclitaxel and cisplatin in patients with advanced non-small cell lung cancer. Genet. Mol. Res. 13: 2796-2805. http://dx.doi. org/10.4238/2014.April.14.8

Cojoc M, Mäbert K, Muders MH and Dubrovska A (2015). A role for cancer stem cells in therapy resistance: cellular and molecular mechanisms. Semin. Cancer Biol. 31: 16-27. http://dx.doi.org/10.1016/j.semcancer.2014.06.004

Coulon A, Flahaut M, Mühlethaler-Mottet A, Meier R, et al. (2011). Functional sphere profiling reveals the complexity of neuroblastoma tumor-initiating cell model. Neoplasia 13: 991-1004. http://dx.doi.org/10.1593/neo.11800

Cui QL, Ye P, Shu QJ and Shao M (2015). Study on inhibitory effect of aqueous extract of Taxus chinensis var. mairei combined erlotnib on A549 xenograft in nude mice and its mechanism. Zhongguo Zhong Xi Yi Jie He Za Zhi 35: 572-577.

Dean M and Annilo T (2005). Evolution of the ATP-binding cassette (ABC) transporter superfamily in vertebrates. Annu. Rev. Genomics Hum. Genet. 6: 123-142. http://dx.doi.org/10.1146/annurev.genom.6.080604.162122

Fan L, Ding S, Ai L and Deng K (2012). Antitumor and immunomodulatory activity of water-soluble polysaccharide from Inonotus obliquus. Carbohyd. Polym. 90: 870-874. http://dx.doi.org/10.1016/j.carbpol.2012.06.013

Hua Y, Yang B, Tang J, Ma Z, et al. (2012). Structural analysis of water-soluble polysaccharides in the fruiting body of Dictyophora indusiata and their in vivo antioxidant activities. Carbohyd. Polym. 87: 343-347. http://dx.doi. org/10.1016/j.carbpol.2011.07.056

Karasawa T and Steyger PS (2015). An integrated view of cisplatin-induced nephrotoxicity and ototoxicity. Toxicol. Lett. 237: 219-227. http://dx.doi.org/10.1016/j.toxlet.2015.06.012

Kuromori T, Ito T, Sugimoto E and Shinozaki K (2011). Arabidopsis mutant of AtABCG26, an ABC transporter gene, is defective in pollen maturation. J. Plant Physiol. 168: 2001-2005. http://dx.doi.org/10.1016/j.jplph.2011.05.014

Martens S and Mithöfer A (2005). Flavones and flavone synthases. Phytochemistry 66: 2399-2407. http://dx.doi. org/10.1016/j.phytochem.2005.07.013

Moserle L, Ghisi M, Amadori A and Indraccolo S (2010). Side population and cancer stem cells: therapeutic implications. Cancer Lett. 288: 1-9. http://dx.doi.org/10.1016/j.canlet.2009.05.020

Nobili S, Landini I, Giglioni B and Mini E (2006). Pharmacological strategies for overcoming multidrug resistance. Curr. Drug Targets 7: 861-879. http://dx.doi.org/10.2174/138945006777709593

Peng ZG, Liu DC, Yao YB, Feng XL, et al. (2016). Paclitaxel induces apoptosis in leukemia cells through a JNK activationdependent pathway. Genet. Mol. Res. 11: 33-37.

Perez-Tomas R (2006). Multidrug resistance: retrospect and prospects in anti-cancer drug treatment. Curr. Med. Chem. 13: 1859-1876. http://dx.doi.org/10.2174/092986706777585077

Singh S and Chellappan S (2014). Lung cancer stem cells: Molecular features and therapeutic targets. Mol. Aspects Med. 39: 50-60. http://dx.doi.org/10.1016/j.mam.2013.08.003

Su G, Zhao Y, Wei J, Han J, et al. (2013). The effect of forced growth of cells into 3D spheres using low attachment surfaces on the acquisition of stemness properties. Biomaterials 34: 3215-3222. http://dx.doi.org/10.1016/j. biomaterials.2013.01.044

Wu C and Alman BA (2010). Side population cells in human cancers. Cancer Lett. 268: 1-9. http://dx.doi.org/10.1016/j. canlet.2008.03.048

Genetics and Molecular Research 15 (3): gmr.15038336 
Xue H, Lu CH and Wu XB (2012). Development and characterization of microsatellite markers for the endangered Chinese yew Taxus chinensis var. mairei (Taxaceae). Genet. Mol. Res. 11: 1296-1269. http://dx.doi.org/10.4238/2012. May.14.3

Zhao C, Li Z, Li C, Yang L, et al. (2015). Optimized extraction of polysaccharides from Taxus chinensis var. mairei fruits and its antitumor activity. Int. J. Biol. Macromol. 5: 192-198. http://dx.doi.org/10.1016/j.ijbiomac.2015.01.043

Genetics and Molecular Research 15 (3): gmr.15038336 